\title{
BMJ Open Stereotyping as a barrier to the social participation of older adults with low vision: a qualitative focus group study
}

\author{
Sarah Fraser, ${ }^{1}$ Irene Beeman, ${ }^{2}$ Kenneth Southall, ${ }^{2}$ Walter Wittich ${ }^{\odot 3,4}$
}

To cite: Fraser S, Beeman I, Southall K, et al. Stereotyping as a barrier to the social participation of older adults with low vision: a qualitative focus group study. BMJ Open 2019;9:e029940. doi:10.1136/ bmjopen-2019-029940

- Prepublication history for this paper is available online. To view these files, please visit the journal online (http://dx.doi org/10.1136/bmjopen-2019029940).

Received 18 February 2019 Revised 25 July 2019 Accepted 26 July 2019

Check for updates

(C) Author(s) (or their employer(s)) 2019. Re-use permitted under CC BY-NC. No commercial re-use. See rights and permissions. Published by BMJ.

${ }^{1}$ Interdisciplinary School of Health Sciences, Faculty of Health Sciences, University of Ottawa, Ottawa, Ontario, Canada ${ }^{2}$ The School of Social Work, Faculty of Arts, McGill University, Montreal, Quebec, Canada

${ }^{3}$ School of Optometry, Faculty of Medicine, Universite de Montreal, Montreal, Quebec, Canada

${ }^{4}$ Centre de recherche interdisciplinaire en réadaptation du Montréal métropolitain, Montreal, Quebec, Canada

Correspondence to

Dr Sarah Fraser;

sarah.fraser@uottawa.ca

\section{ABSTRACT}

Objective In order to better understand the barriers that limit the social participation of older people with low vision, the aim of this study was to describe and clarify the factors that shape the social participation of older adults with vision loss.

Methods As part of a study on rehabilitation access barriers, six qualitative focus groups were conducted in a private room in a hospital, with 21 individuals with low vision (aged 38-92 years) who had or had not accessed low vision services. During the focus groups, participants often spoke of the challenges they faced when interacting with people with 'normal' vision; this discussion led to a modification of the interview guide in order to capture barriers to social participation. Focus group discussions were audiotaped and transcribed, and content analysis was conducted.

Results Content analysis revealed that personal as well as environmental factors influenced the social participation of older adults with low vision. Four themes emerged: 1) experiencing the onset of impairment and degenerating ability, 2) the physical environment, 3) attitudes and responses from others and 4) individual internal attitude and responses during social interactions. Lived and perceived stigma from the perspective of the insider (person living with low vision) interacting with an outsider (person with 'normal' vision) and difficult environmental contexts were described as barriers to social participation and optimal functioning.

Conclusion At a personal level, transitioning from an outsider to an insider influenced self-identity and social participation. Further, insiders experiencing stereotypes associated with older adults who are blind had a negative impact on their social participation. Findings highlight the importance of stigma and stereotyping in the lived experience of older adults with low vision. Stigma is persistent, but strategies to reduce stigma will ultimately facilitate the social participation of older adults with low vision.

\section{INTRODUCTION}

Functionally, a person with low vision can be defined as someone "who has difficulty accomplishing visual tasks, even with prescribed corrective lenses, but who can enhance his or her ability to accomplish these tasks with the use of compensatory visual strategies, low vision and other assistive

\section{Strengths and limitations of this study}

The relevance of this secondary analysis emerged through the unsolicited nature and priority of focus group participants to provide rich data on the important factors influencing social participation among individuals with low vision.

- Qualitative focus group data provide a raw and personal perspective and insight on the experience of social participation and social isolation of older adults with low vision.

- Given the focus on older participants with acquired visual impairment, the presented perspective on social participation may not generalise to persons with congenital visual impairment of all ages.

- Though stereotyping emerged as an important theme, this dimension was not specifically solicited during the interview process and may be under-represented in this data set.

devices, and environmental modifications, ${ }^{1}$ (p4). In order to study these factors that influence outcomes for an older individual with low vision, a suitable framework needs to encompass these varied aspects. One commonly used framework is the International Classification of Functioning, Disability and Health (ICF) from the WHO. ${ }^{2}$ The ICF takes into account functional factors (ie, low vision, participation) as well as contextual factors (ie, the environment and personal factors) and has been applied to populations with low vision. ${ }^{3}{ }^{4}$ In the ICF, participation has been defined as 'involvement in a life situation' (p8, 10) and encompasses social participation elements such as interpersonal interactions and relationships as well as involvement in community, social and civic life. ${ }^{2}$ Psychological health and social participation are both functional factors that can potentially be negatively affected by vision loss. Numerous studies have highlighted the increased risk for depression among older persons with visual impairment, ${ }^{5-8}$ in addition to decreased perception of quality of life. ${ }^{9}$ Participation restrictions in particular 
have been shown to be linked to psychological well-being in older adults with visual impairment ${ }^{10}$ who are often limited in their ability to get around independently, especially in new environments, making it more difficult to attend social functions.

In addition, for individuals with acquired vision loss (ie, age-related macular degeneration, glaucoma, diabetic retinopathy, stroke-related vision loss), their impairment may affect communication strategies, such as face recognition and the ability to distinguish facial expressions, critical for social interaction. ${ }^{11-13}$ Communication challenges and other aspects of life with visual impairment can threaten social participation, thereby possibly isolating the person, negatively affecting their health and reducing their degree of engagement with society. ${ }^{14}$ During low vision rehabilitation, various intervention approaches and tools have the potential to assist the person with low vision to overcome the many barriers they may face and/or perceive, including barriers to social participation. ${ }^{15}$ For example, day centre services that are adapted for older adults with sensory loss have shown promise in maintaining functional abilities and social integration over time, ${ }^{16}$ and a multidisciplinary rehabilitation approach (including ophthalmology, optometry, occupational therapy, low vision therapy, orientation and mobility, orthoptics, and welfare and mental health specialists) has been shown to improve quality of life as well as social participation. ${ }^{17} 18$

Despite the availability of effective rehabilitation approaches, one environmental barrier that may restrict engagement in low vision rehabilitation is the stigma and stereotypes associated with their health status. ${ }^{19} 20$ Stigma occurs when an individual or group has a characteristic (ie, low vision) that is devalued in certain social contexts. ${ }^{21}$ Chronic age-related health conditions, such as vision loss, are commonly stigmatised ${ }^{22-25}$ Stereotypes about disability are learnt at a young age due to persistent sociocultural conditioning. ${ }^{26}{ }^{27}$ In Western cultures, the media portray individuals with disabilities as sick, helpless and in pain. ${ }^{28}$ These stereotypes often result in marginalisation and social exclusion. ${ }^{29-31}$ People who have a visual impairment may come to expect discrimination, creating a self-fulfilling prophecy. ${ }^{32-34}$ Anticipating situations of stigma may have negative impacts on quality of life as older adults with low vision may forego opportunities for social participation. In recent years, increasing attention has been paid to patient-centred outcome measures and an involvement of patients as research partners through participatory action research. ${ }^{35}$ In visual impairment research, this trend has allowed researchers to pay closer attention to insider perspectives (eg, the viewpoint of persons with the visual impairment) as part of the research process in domains such as information access $^{36}$ or quality of life. ${ }^{37}$ However, this perspective remains under-represented in the peer-reviewed literature and would be specifically pertinent in the context of stigmatisation.

\section{The origins of low vision stigmatisation}

As with many other chronic impairments, the general public does not easily make the distinction between absolute and partial loss of function. ${ }^{38-40}$ As a result, the general public may stigmatise people with partial vision loss in the same manner that they would stigmatise people who are blind. Stigma is a social phenomenon that is greatly influenced by both historical and cultural forces. ${ }^{41}$ Present-day stereotypes attributed to people with any level of vision loss date back to prejudicial attitudes held against people who were considered blind in Ancient Greek societies. ${ }^{43}$ We now live in a society that relies on traditional communication, such as vocalised speech and eye contact (which is often difficult or unknown to individuals with partial or complete vision loss), whereby stereotypes are housed and maintained within language ${ }^{44}$ Should one encounter a person who is unable to communicate in a 'normal' manner, one might revert to (or rely on) historically and culturally constructed stereotypes in order to understand what is perceived to be 'deviant' behaviours. Like other cultural beliefs, prejudicial beliefs are transmitted from one generation to the next. There is evidence that derivations of ancient prejudices toward people who are blind continue to impact on the present-day community and are extended to include persons with partial vision as well. Kent ${ }^{43}$ reviewed literary references to blindness and found that a lack of sight was almost always framed in a negative fashion. In some ways, the stereotypes about people who are blind have impacted the perception of all people who have vision loss, in part rooted in preconceived ideas and a lack of awareness about persons with low vision, resulting in the exclusion of both groups (for several relevant research articles on stigma and low vision, please see the following resource from the Royal National Institute for the blind: https://www.rnib.org.uk/professionals/knowledge-and-research-hub).

Critical to the experience of stigmatisation is social context. Characteristics of the physical and social environment influence the meanings assigned to situations and events by those present. ${ }^{45}$ For example, the nature of marginalisation and mistreatment is likely different when a person who has a stigmatising trait is interacting with friends and family, as opposed to that same person interacting with a group of strangers. The extent to which a person is familiar with people who have the stigmatising trait is an important consideration when assessing how threatened an individual will feel by the presence of stigma. ${ }^{46}$ Some may decrease their stigmatisation because they are familiar with people who have the stigmatising trait while others will increase it based on their previous negative interactions with a person with low vision.

In a previous study, members of this team sought to explore older adults' perspectives on the barriers to low vision rehabilitation. Focus group participants described stressful or negative interactions with people with 'normal' vision in which they felt they were being negatively judged due to their vision status. ${ }^{19}$ These descriptions were unsolicited (as this was not the goal of the study), but we 
recognised a pattern emerging early on in our data analysis and modified our interview guide in order to include follow-up questions to further explore this issue as data collection progressed. Given the unprompted nature of the data and the lack of research on this topic, we deemed that the descriptions of social interactions would provide more information on the stigma perceived and/or experienced by older adults with low vision. Given the relative paucity of research on the stigma associated with low vision and the important implications for the rehabilitation and social participation for this population, as well as the rich detail arising from these interviews, we decided to conduct a secondary analysis of the focus group interviews from Southall and Wittich. ${ }^{19}$ The aim of the study was to describe and better understand the factors that shape the social participation of older people with vision loss. This understanding would provide a more holistic comprehension of functioning that considers the person, the impairment and the environment to promote the health and well-being of older adults with vision loss.

\section{METHODS}

Secondary analysis of qualitative data is a common qualitative methodology procedure, ${ }^{47}$ whereby the analysis of an existing data set allows for examination of a topic different than that of the original project. ${ }^{48}$ The methods and results follow the COnsolidated criteria for REporting Qualitative research (COREQ) guidelines: a 32-item comprehensive checklist used in the reporting of data from interviews and focus groups. ${ }^{49}$ During the focus group sessions and on revisiting the original transcripts, it was obvious that most participants provided in-depth narratives about their interactions with other individuals in their community who have 'normal' vision. This interaction between people with low vision and those with 'normal' vision became the focus of this investigation.

\section{Participants}

The focus group participants were recruited through their involvement in the Montreal Barriers Study ${ }^{50}$ and all provided written and informed consent. Each focus group was composed of participants who had not heard of low vision rehabilitation services, had heard of but not accessed these services or who knew of and accessed these services. Six focus groups of two to five participants were conducted with a total of 21 participants (14 women, 7 men), ranging in age from 38 to 92 years (please note: only one participant (age: 38 years) was under the age of 65 years; given the similarity of her response content to that of all other participants, her data were maintained in the analyses). Participant characteristics are presented in table 1. Heterogeneous groups were selected so that differences in perspectives on the barriers to low vision rehabilitation services would be most apparent to the investigators during the focus group discussions and subsequent analyses.

\section{Data collection}

As described in the original protocol, ${ }^{19}$ the team members with the most extensive experience as a qualitative researcher (KS) led focus groups. The principal topic of interest (positive and negative perceptions on low vision rehabilitation) was explained to participants, including the central three questions: What enabled you to access low vision rehabilitation services? What served as obstacles to you accessing low vision rehabilitation services? and What could be done to make it easier to access low vision rehabilitation services? The research team aimed to create an informal and comfortable atmosphere, allowing participants to freely discuss and share their perceptions, while encouraging discussion among the participants. At the beginning of the focus group session, to facilitate communication for people with visual impairments, it was stated that all cues would be auditory and that there would be turn taking so that only one person spoke at a time. All participants introduced themselves to facilitate auditory localisation of each individual and to let participants become more familiar with everyone's tone of voice. The participant or the leader of the group would state the name of the person speaking and anyone who wished to comment could raise their hand and the leader would facilitate their turn in speaking. During focus group discussions, barriers to social participation were described by the participants, as such the interview guide was modified to include questions about barriers to social participation and interactions with people with 'normal' vision. Focus groups were conducted in a private room at the Jewish General Hospital in Montreal (Canada). Each focus group had one group discussion session that lasted $60-90 \mathrm{~min}$. In addition, field notes were taken by the last author (WW) as a secondary data source to supplement the audio-recorded information. ${ }^{51}$ During verbatim transcription, identifying information was removed to ensure confidentiality, while proper names were replaced with pseudonyms.

\section{Analyses}

For the present study, we employed qualitative content analysis of the interview transcripts ${ }^{52}$ to describe and better understand the factors that shape the social participation of people with vision loss. Content analysis involves open coding when the researchers familiarise themselves with the data and identify narratives that answer the question. ${ }^{53}$ In the margins of interview transcripts, labels were assigned to relevant data. The aim was to assign the necessary labels so as to describe fully the content of the text. ${ }^{54}$ Next, categories of codes were created in order to generate manageable chunks of information..$^{55}$ The final phase involved extracting general descriptors of the data. To this end, we uploaded the data into ATLAS.ti ${ }^{56}$ a software programme that is designed to aid in the analysis of large bodies of text and to identify meaningful patterns within and across the transcripts of interviews. A number of representative interview excerpts were selected for inclusion in the Results section. ${ }^{53}$ All data analyses were 


\begin{tabular}{|c|c|c|c|c|}
\hline Participants & Diagnosis & Gender & Awareness & Accessed \\
\hline 1 & $\mathrm{RP}$ & Female & Yes & Yes \\
\hline 2 & $\mathrm{DR} / \mathrm{GL}$ & Male & Yes & Yes \\
\hline 3 & Stroke & Female & Yes & Yes \\
\hline 4 & $\mathrm{RD} / \mathrm{DR} / \mathrm{GL}$ & Female & Yes & Yes \\
\hline 5 & $\mathrm{DR} / \mathrm{GL}$ & Female & Yes & Yes \\
\hline 6 & AMD & Male & Yes & No \\
\hline 7 & AMD & Female & Yes & Yes \\
\hline 8 & $\mathrm{GL}$ & Female & No & No \\
\hline 9 & AMD & Male & No & No \\
\hline 10 & Ocular trauma & Male & Yes & Yes \\
\hline 11 & Corneal transplant/keratitis & Female & Yes & Yes \\
\hline 12 & AMD & Female & Yes & Yes \\
\hline 13 & $\mathrm{AMD} / \mathrm{GL}$ & Female & Yes & Yes \\
\hline 14 & AMD/RD & Female & Yes & Yes \\
\hline 15 & AMD/GL & Female & Yes & Yes \\
\hline 16 & GL & Male & Yes & Yes \\
\hline 17 & AMD & Female & Yes & Yes \\
\hline 18 & AMD & Female & Yes & Yes \\
\hline 19 & DR & Male & Yes & Yes \\
\hline 20 & AMD & Male & Yes & Yes \\
\hline 21 & AMD & Female & Yes & Yes \\
\hline
\end{tabular}

Accessed, accessed low vision services (yes or no); Awareness, aware of rehabilitation services for vision loss (yes or no).

AMD, age-related macular degeneration; DR, diabetic retinopathy; GL, glaucoma; RD, retinal detachment; RP, retinitis pigmentosa.

conducted by two of the co-authors (KS and WW) in faceto-face meetings, whereby team coding was performed, discussions about different ways of 'seeing' the data were explored and discrepancies were resolved through discussion and presentation of rationale for items being addressed, a technique the authors have successfully implemented before. ${ }^{5-59}$

\section{Patient and public involvement}

This research was done without patient involvement. Patients were not invited to comment on the study design and were not consulted to develop patient-relevant outcomes or interpret the results. Patients were not invited to contribute to the writing or editing of this document for readability or accuracy. However, indirectly, the study was driven by patient priorities, given that the content on stigma and social participation was unsolicited but substantial enough to warrant secondary analyses.

\section{RESULTS}

In this study, we sought to answer the research question 'What are the factors that shape the social participation of people with vision loss?' Our analyses uncovered four interwoven factors that shape social participation for this sample, including (1) experiencing the onset of impairment and degenerating ability, (2) the physical environment, (3) attitudes and responses from others and (4) individual internal attitude and responses during social interactions. These findings further suggest that, depending on the nature and interactions of these factors, the social participation of people with vision loss may be described anywhere on a spectrum from empowering to disabling.

Experiencing the onset of impairment and degenerating ability The first theme represents changes in functional status, self-reflections and the emotions associated with transitioning from a person with 'normal' vision to one that has reduced visual abilities. In terms of changes in functional abilities, participants described 'losses' and their ability to perform social roles as well as activities of daily living. These changes initially resulted in negative emotions, such as frustration, feelings of helplessness and hopelessness shortly after the onset of the impairment. In the paragraphs that follow, we provide excerpts that demonstrate the intersections of stereotypes associated with vision loss, as well as the desire and need for social participation.

Focus group participants revealed the ways in which the experience of losing vision impacted their social participation. All participants experienced the onset of 
vision loss later in life and therefore had to adjust to the (emotional and psychological) loss of a previously experienced ability. Later, the onset of vision loss resulted in participants being unable to engage in their daily activities in the same way they did prior to vision loss. For example, one participant indicated that the experience of impairment can be particularly devastating later in life, whereby her 'whole world' appears to crumble, stating:

I am going to be 77 years old. I had my eyesight for 76 years and now I lost it and losing it... When I found out I felt like my whole world was crumbling from under me and I said how am I going to survive?

Another participant described an example of engagement in social activities and roles, whereby she was not seeing well enough to read, cook or drive as she believes she should be able to. She said, 'I renewed my (driving) license in February and in March I cancelled it myself because I couldn't see too clear. That hurt me a lot.'

For another participant, not being able to do things in the way he used to made him feel ridiculous,

You cannot do things that you normally would think of, like, for example, I have to go to the cleaners to bring my cleaning. Am I going to hire a driver or take a taxi that is five blocks or six blocks because I have spinal stenosis so that I cannot walk a lot of blocks? I mean you feel ridiculous, you know.

At times, even when it was possible to accomplish habitual tasks in new ways, individuals may struggle with a great sense of helplessness and the commonly held perception that nothing can be done to improve their visual abilities. One participant recalled,

One woman, I will never forget that...I walked into the support group. All the woman was doing was crying because she couldn't peel a potato and an onion. Lady, get with it. She cried for a whole hour because she couldn't peel that potato. That potato was so important to her, it was her whole life. All she was worried about, I can't peel the potato... The lady that was running the program was telling her that there are so many alternatives out there that you can do with that potato. There is electric this, there is a special peeler, I can show you techniques and then she started screaming at that poor lady. What do you know about blindness? Are you blind? Do you know what I am going through?

In addition to its later onset, the degenerative nature of visual impairment among participants meant that ability and functioning are not static, which required continual adjustment. One individual described the challenge of coping with gradually shifting visual ability.

It's hard. It's really, really hard, you know. It changes your life. It's a struggle every single day for me. I get up in the morning and I struggle... you got to put in your mind that you can't go back. You can say, well last week I saw this, this and this and this week I can't. You cannot dwell on that.

\section{Physical environment}

The second theme represents the intersection of the physical environment, commonly accepted beliefs people hold about visual impairment and their perceived influence on social participation. This includes the social participation for people with vision loss in the physical environment, particularly in terms of the ways in which the public physical environment is constructed. For example, participants described encountering barriers to mobility in the way public transportation is designed and structured, such as streets, sidewalks, buses and the subway. One person explained, 'You take the bus; you don't know what number you are getting onto. I ask the driver all the time. To cross the street is very difficult.' Another added, 'I have been once nearly run over... so this is a dangerous thing', highlighting the perceived vulnerability of this population when engaging in social encounters in public spaces. Participants also described the numerous disabling ways in which other public spaces are constructed, including elevators, grocery stores, banks, pharmacies, restaurants and recreation centres, pointing at the inequalities that persons with visual impairment encounter on a daily basis. One individual recounted a commonly encountered experience among participants, stating, 'I went into a store two weeks ago and I didn't know where the cashes are, I could not find anything. I could not find the exit.'

One woman further articulated how the publicly shared physical environment is often structured in ways that result in the social exclusion of those who are not 'normal': those with vision loss. She described,

When I was growing up, people would talk about integration: how to bring a handicapped person into the regular world. That is very nice, it's all nice and well and it's a great project. The only problem is that when you do grow up and you want to be in the normal world, example again for the gym, well I am told - I am sorry we can't help you so go to your visually impaired centers and let them help you. And you know I can't go shopping on my own anymore. I have to have somebody sighted with me because I literally get lost in the store. So, this is what I find, it's very hard. It's... all my life I have been told go, go, go and I went, went, went and now that I am actually losing my eyesight, I am at the point where I need help, I am told, sorry by the regular world. Sorry we can't help you so go back to your people, go back to your kind and stay there.

Some participants made a distinction between the impacts of the impairment itself and the impacts of environmental conditions on their social participation. For many participants, challenges in the physical environment in public spaces resulted in them retreating to the private sphere, for example, at home, where they could 
exert more control over the way in which the environment is constructed and therefore experience greater comfort and better functioning. One participant said, 'I was hiding at home because at home I felt secure and I could do my chores and listen to classical music." Similarly, another participant described that, rather than facing the various environmental barriers involved in going out as she used to, 'I do not see my good friends anymore. I talk to them over the phone but I don't see them.'

\section{Attitudes and responses of others}

This third theme represents social attitudes and responses that impact the social participation of other people as persons with vision loss encounter them. Participants described misunderstandings and unwanted attention from others based on their visual impairment. Additionally, some participants reported being treated with disgust or disrespect by people with 'normal' vision. One male participant described what he felt was a lack of understanding and that individuals like him are not worthy of the respect of others. He described a situation on public transportation,

[passengers with 'normal' vision] don't get up. They tell a legally blind person to go to the back of the bus which they have to watch for their stop, you know, and you got to push your way through their backpacks, they hit you on the head, they hit the dog in the head. You got to fight every chap on that bus.

Another individual suggested that ignorance and stigmatising attitudes that exist regarding people with vision loss potentially result in social exclusion and in interruption to the natural flow of communication,

When you're visually impaired it's like, you drink out of my cup, you are going to get it. It's contagious, if I touch you, I sneeze on you, that's it, tomorrow you are going to be blind. That's the conception out there.

Such negative attitudes and responses from others created a hostile social participation experience for this group of people with vision loss. One individual further illustrates this in the following passage,

People don't respect (people with vision loss). You go downstairs, they may push you and make you fall down. Or in the bus. Now I have my little low vision card. My low vision card, it helps me but not very much. People do not respect the elderly people first of all and the people that have problem eyesight. They don't respect all the handicapped people. And this just makes your daily life miserable (sic).

Having previously encountered negative attitudes, some participants indicated that at some point they began to anticipate being devalued by others in social settings and that the strategy most often employed to mitigate this risk was to hide their vision loss from others. One participant remarked, 'I have a friend... he has been blind his whole life... and he used to say he doesn't want to use a cane or dog because he doesn't want people to know that he has a disability.' Another participant describes an attempt to hide his impairment, saying,

I try to ask strangers to do something for me and I am going to find one excuse... Oh I'm sorry I don't have my reading glasses, or something like this, please you do it for me...I don't want to tell them I can't see (sic).

One participant explained how feeling misunderstood or rejected by people with 'normal' vision caused her to disconnect from relationships that had previously been very important to her. She stated,

People who are well don't know what this is like. They don't want to hear it. They have their own problems. You understand, that's the truth. My own dear friends, I don't discuss anything with them about my eyes. That's why I don't want to see them anymore.

Some participants indicated that among individuals with 'normal' vision, even those who have positive intentions, their response can have a negative impact on the social participation of older adults with vision loss. One participant recalled,

I was coming home late... and this person comes up behind, the man, I know he wanted to help me, poor guy. He came up behind me but he put his hand on my shoulder but so aggressively and at that time, I was actually studying judo. I grabbed the guy's arm and I flipped him and passed him over me and the guy is lying on the floor and I'm like, 'Don't ever do that again.' He said, 'I just wanted to help.'

\section{Individual internal attitude and responses}

The fourth theme represents the intersection of personal beliefs and attitudes about visual impairment and its impact. Some participants described an understanding that not everyone responds to the onset of visual impairment the same way. Responses are influenced by personal characteristics, such as personality, age, gender, as well as by an internal or external locus of control. Some may perceive themselves as potential victims or may choose to overcome that perception by consciously engaging in proactive coping mechanisms. One participant asserted, 'A lot of it has to be up to the individual,' as well as, 'You know I have a little bit of chutzpah, you know, a little bit of nerve...You know what? It's helped me.' Similarly, another participant described,

I would say, to be honest, I think it depends on your state of mind. It depends if you are willing to say, 'ok this is my problem'. I was just going to say, as I said, eventually you have two choices; it's either you stand up and fight and say, 'if you can't help me, who can?' and find out what you can and cannot do, or you sit in your little corner and say, 'poor me'. 
One participant explained that her outlook changed over time. When she first began experiencing vision loss, she felt discouraged and powerless, which, in turn, impacted her social participation. With time, she described acquiring more of a fighting spirit, stating that her current outlook is,

I just turned 65, my life is not over it's just starting. All my friends are retiring and I am going back to school and get my Masters and I want to work with kids who are at risk. I have a lot still to do and if I lose my vision completely, I feel that I am prepared, I have the dog, and I have the JAWS program. I don't need my husband by my side any more. Because that's what I used for a long time and I was dragging him around. He's got his own work.

A central idea iterated among participants in terms of personal attitude was the importance of fighting to maintain independence rather than relying completely on others. One person said, 'What I found is like they have said, you have to keep your independence.' Another agreed, stating,

My pride went on the backburner, when I realized that I was dependent on someone. I wanted my independence back. I gave up driving a car, too. So when I started thinking about the car and how I felt and all the things that I had to give up, so I said, 'No, I don't have to give up, I have to learn how to do things.'

However, participants also expressed that while personal attitudes shaped experience, this was not the only influencing factor. A fighting spirit, positive outlook and determination to be independent cannot overcome all of the obstacles to social participation experienced by older adults with vision loss. One person stated,

'The only thing that I find very hard is when you are losing your eyesight, there are a lot of things that, no matter how much you want to be independent, you can't.'

\section{DISCUSSION}

The purpose of this study was to describe and better understand the factors that shape the social participation of older adults with vision loss. Our findings suggest that respondents experience social participation through the personal lens of transition from an outsider (someone with 'normal' vision) to an insider (someone with low vision). Our findings also document stereotyping, both from insiders (persons with low vision) and outsiders (people with 'normal' vision). These (primarily) negative assumptions that others may make seemed to have an important influence on their social participation. Two social settings: family and friends (private setting) versus the public at large emerged as important to the individuals in our sample. The analyses revealed that the onset of vision loss initiates changes in the individual who has the impairment (as they become an insider), as well as how others (the outsiders) perceive this person. These analyses also highlight that there exist both internal and external factors that influence the nature of social participation for an individual with low vision, as characterised in the ICF with the personal and environmental factors.

\section{Personal factor: adapting to change with the onset of impairment}

Individuals perceive themselves as insiders or outsiders based on characteristics they believe they have that aligns them with one or the other groups. ${ }^{21}$ Their identity is in jeopardy when they are in limbo or transitioning, somewhere between perceiving themselves as a person with 'normal' vision or a person with acquired vision loss. This threatens their identity as they are uncertain as to what this 'new' version of themselves will be. When people who have vision loss find themselves in social settings with those who have 'normal vision', tension can arise. For the insider, a number of factors may contribute to this tension, including that the insider has not yet accepted the loss, and may not yet be comfortable using assistive technologies or orientation strategies to facilitate and reduce this tension and facilitate social participation. ${ }^{60-62}$

Within the context of family and friends, the onset of impairment gave rise to the perceived stereotype of being helpless, as described by the participants, specifically in the context of maintaining and performing social roles. This supports what we know from the research literature, ${ }^{4363}$ whereby previous reports have highlighted the stereotype maintained in folklore writings that people with visual impairment are helpless. ${ }^{42}$ In the example of our participant who described her experience of feeling (and being perceived as) helpless in the context of kitchen work, this stereotype may be threatening her social role in one specific setting but may not exist in a different setting, depending on what the context may be. In some instances, people with low vision will construct environments (with the help of rehabilitation services), whereby they have optimal control over their level of functioning, thereby limiting the possible threat of task failure, improving their adaptation to change and diminishing the resulting stereotyping in social situations. ${ }^{64}$

Within the public at large, stereotypes about people with low vision have also previously been described in the literature, such as people with low vision are disabled, all the same, contagious, old and dependent. ${ }^{206566}$ There is a history of tension, discrimination, marginalisation and institutionalisation that informs and guides interactions between people with visual impairment (insider) and those with 'normal' vision (outsider) groups. ${ }^{21}$ For the insiders, in line with research on disability, ${ }^{67}$ the individuals with low vision in our sample do not want to be thought of as different or as dependent. This desire may make it difficult for an individual who is experiencing the onset/progression of vision loss to accept the situation. ${ }^{60}$ There is great variability of social responsiveness to being stereotyped. Insiders may respond differently to stereotyping depending on the length of time since diagnosis. 
It is 'normal' with people with vision loss to wait for years before seeking help from low vision rehabilitation services. ${ }^{65}$ Presumably, during this time the individuals' identity is changing. The extent to which the new identity of the person with vision loss has been integrated into the individual's social identity will shape their responses to stereotyping. ${ }^{68} 69$

\section{Environmental factors: public stigma \& physical environment}

The most apparent difference between private and public setting categories as they relate to our findings is the degree of familiarity outsider groups have with insiders who have low vision. Familiarity is a topic that has been previously explored as it relates to stereotype threat. ${ }^{70}$ Stereotype threat is a real or perceived threat of being judged and treated badly in 'settings where negative stereotypes about one's group applies' (p385, 70 ). Outsider groups are presumed to have knowledge of the stereotypes about the health condition and its treatment and may be familiar with the individual. This line of research suggests that familiarity impacts on likelihood of stereotyping another individual. ${ }^{71} 72$ Many of the passages from the participants describe outsiders as being unfamiliar with visual impairment and/or relying on preconceived notions of vision loss. The perception was that many individuals with 'normal' vision simply do not understand that only a small percentage of people with vision loss are totally blind and that the remainder have various levels of remaining visual function or functional vision. ${ }^{73-75}$ For most outsiders, their understanding is that people are either blind or have 'normal' vision. ${ }^{75}$ So any manifestation or use of rehabilitation strategies employed by people with vision loss may lead outsiders to assign the label of blind and contemplate all of the associated stereotypes. This public stigma can hinder the helpseeking process of people with low vision, as they may actively avoid these negative stereotypes by not identifying themselves as an insider. This is commonly apparent when deciding to adopt a white cane for mobility, ${ }^{76}$ which identifies a person as having an impairment in vision. Within our sample, one person experiencing changes in their vision actually identified with a friend who did not use a cane or a guide dog to avoid being singled out as disabled. While the cane or guide dog can improve function and participation, its use may be circumvented to avoid the larger problem of stigma.

With respect to the present findings, two points about insiders are particularly noteworthy. First, individuals with acquired disability have been shown to differ in their perception of and approach towards their disability and their disability identity ${ }^{77}$; however, this topic has not been extensively in the context of visual impairment. ${ }^{78}$ Research by Bogart ${ }^{77}$ suggests that people with a congenital mobility disability report having a higher satisfaction with life, a better disability identity and disability self-efficacy than people with acquired mobility disabilities. The authors suggest that those with congenital disabilities have adapted to and take pride in their disability identity. In contrast, those with acquired disabilities may be influenced by rehabilitation professionals attempt to 'normalise' people and have more difficulty adapting to their new identity. ${ }^{77}$ Our participants with acquired vision loss, however, are likely differentially impacted by stereotyping compared with those living with congenital impairment, specifically as their experience of loss differs. These individuals initially had 'normal' vision and have thus been part of the outsiders' group. They themselves may have stereotyped others for vision impairment in the past. Second, according to the modified labelling theory, ${ }^{79}$ when stereotyping does occur (in both public and private settings), this confirms insider expectations and may lead insiders to expect future stereotyping. This can lead to a self-fulfilling prophecy, whereby insiders subconsciously expect persistent stereotyping in both public and private settings and make decisions that result in negative outcomes such as social isolation, reduced social engagement and self-stigmatisation. The quotes exemplify that some do ask 'strangers' for help but without revealing their impairment or not talking to their friends anymore because 'People who are well don't know what this is like. They don't want to hear it.'

For insiders, perhaps past experiences of stereotyping with people who have 'normal' vision have left an emotional scar, which makes it difficult to interact normally. Outsiders may not be sure how to approach a person with vision loss, may not know how to help or even to offer help. This is clear in the example where an outsider grabs the shoulder of a participant with low vision (insider), resulting in a negative experience for both. The outsider may also experience shame for considering stereotypes. Participants' accounts of stereotyping in private settings are consistent with familiarity and the modified labelling theory. There was a virtual consensus that people with 'normal' vision, even those who have a close connection with an insider, do not understand the realities of visual impairments, their treatment and do not know how to assist a person with vision loss. While it is reasonable to assume that most people have good intentions, this lack of knowledge about low vision can contribute to stereotyping.

Characteristics of the environment in which the social interaction takes place may also come into play. This is not surprising, since those who design the built environment (typically outsiders with power) assume 'normalcy' and ignore the potential of universal design that would make the physical environment accessible to all people. ${ }^{80}$ Several quotes in our findings illustrate that physical environments are often structured in inaccessible ways for people with vision loss and that this structure contributed to reduced mobility, independence and sense of security for these individuals. In addition, contextual factors such as the number of people present, the purpose of the event, as well as the presence of other people who have vision loss or knowledge of vision loss all factor into potential stereotyping. Moreover, all of these factors may give rise to the level of stress for both the insiders and the outsiders. 
For example, one participant discussed transportation as stressful and described their reliance on the bus driver or others for help. According to the stigma-induced identity threat model,$^{81}$ the balance between demands of the situation and personal resources will determine the level of identity threat and will in many ways govern responses by both insiders and outsiders.

\section{Reducing the barriers to social participation of older adults with low vision}

It remains unclear how older adults with vision loss should approach social interactions knowing and expecting that assumptions will be made about them and that some of these assumptions will be erroneous and potentially marginalising. It is our contention that older adults with vision loss may be best served by repeatedly disclosing to others relevant information about their low vision and how communication partners can aid them in their social participation thereby advocating for themselves. In the stigma reduction literature ${ }^{63}$ there is a general consensus that stigma reduction campaigns should incorporate four types of activities: educational and awareness campaigns, face-to-face interactions or personal contact, persuasion (changing people's beliefs about low vision) and disability simulations (have outsiders, in particular familiar outsiders, experience what it is like to have low vision). Wainapel ${ }^{76}$ proposed that peers may be best situated to counsel a newly diagnosed person. However, the findings from the present study, and from previous work on familiarity and stereotyping, suggest that relying only on one-to-one interactions to reduce the stigma associated with low vision might not be advisable. It is possible that stigma reduction may only result from more intimate, or at least developed, connections with people who have stigmatising traits. If this is the case, stigma reduction programme might test building on existing relations with people who have stigmatising traits. With respect to outsiders who are unfamiliar with visual impairment, increased education, persuasion from the insider about their capabilities and experiential trials that simulate low vision can help reduce these environmental barriers to social participation for older adults with low vision.

\section{Clinical implications: importance to rehabilitation of clients with low vision}

In some cases, stereotyping extends into clinical/healthcare settings. ${ }^{82}$ Familiarity with visual impairments and the manifestations of low vision combined with a charged daily appointment list may lead some clinicians to make assumptions about the challenges and abilities of their clients. Stereotyping by clinicians will reduce opportunities for client-centred care for people with low vision. It is therefore vital to increase the awareness of stereotyping and its pitfalls by clinicians who work with individuals who have low vision. All clinicians should assess their own attitudes toward this population. Recent work ${ }^{83}$ with healthcare providers suggests that some professionals may not adopt stereotypical views of their clients.
This work, in dual sensory impairment (DSI: combined hearing and vision losses), suggests that strong familiarity with a marginalised group (in this case older adults with DSI) can actually be an asset. Many of the professionals that were interviewed were strong advocates for their clients and generally did not seem to have a stereotypical approach to their clientele. However, several mentioned the daily public stigma their clients faced and that interactions with professionals not specifically trained in DSI often resulted in stereotypical responses. ${ }^{83}$

Even the most perfectly rehabilitated client at a functional level may remain fearful of being identified, faced with barriers created by the sighted community and socially excluded. Rehabilitation specialists should consider the different spheres in which the individual needs to function and the professionals need to frame their interventions accordingly, with a client-centred approach that supports a respectful partnership between client and healthcare professionals. ${ }^{84}$ Professionals that work with clients with low vision should, based on the clients' needs, encourage attempting different devices and strategies to reduce and/or minimise the barriers faced and help older adults with low vision to be active participants in their physical and social environment. ${ }^{85}$

\section{Limitations}

One potential limitation of secondary analyses of qualitative data sets concerns theoretical saturation. ${ }^{48}$ Content analysis involves identification of incidents, events activities that are grouped to form categories. The category is 'saturated' when new information that adds to the understanding of the category is not forthcoming. If the data set is being used 'inappropriately', there will be limited data, resulting in a premature saturation of the category. This was not a concern for this data set. The participants in this study were proud to discuss their experiences of low vision and social participation. There was thus ample information to analyse. However, the initial focus of data collection was not to probe into the topic of stigmatisation; therefore, it is possible that some aspects of low vision and stigmatisation, beyond the topics that were spontaneously self-identified by our participants, are not covered in our data but might emerge in future studies designed to address this topic in more depth. Future studies should target this area of inquiry directly and ideally have several focus group sessions to increase the amount of data acquired.

\section{CONCLUSION}

Older adults with low vision experience a number of changes when they begin to demonstrate functional impairments in their vision. From the perspective of the participants in our study (the insiders), their personal perceptions transitioning to an insider, as well as their interactions with people with 'normal' vision (outsiders) influence their social participation. The stereotypes and stigma that surround low vision was clearly a topic that 
negatively influenced our participants' social participation as this was a topic that they repeatedly discussed in our focus groups and as a result became a secondary analysis from this data set. Stigma in the environment perceived or experienced is a critical factor to address for older adults with low vision as it has the potential to reduce social participation, in some cases diminish help-seeking and ultimately impact health. Strategies to improve awareness and educate the general public and healthcare providers on low vision could reduce the stigma associated with this condition and ultimately improve the health of older individuals with low vision.

Contributors KS and WW planned this project. KS led the focus groups and KS and WW analysed the data and created the code list together. IB was a graduate student learning qualitative research, and she worked directly with KS to create a rough draft of this paper. SF was involved in the write-up of this project and worked with KS and WW to revise, edit and produce the final version of this manuscript.

Funding This work was supported by a provincial grant from the Fonds de recherche en Santé du Québec. Funders were not involved in data collection, interpretation or reporting.

Competing interests None declared.

Ethics approval The Centre de recherche interdisciplinaire en réadaptation (CRIR) du Montréal métropolitain provided ethical approval for the focus group study protocol.

Provenance and peer review Not commissioned; externally peer reviewed.

Data availability statement Data are available upon reasonable request.

Open access This is an open access article distributed in accordance with the Creative Commons Attribution Non Commercial (CC BY-NC 4.0) license, which permits others to distribute, remix, adapt, build upon this work non-commercially, and license their derivative works on different terms, provided the original work is properly cited, appropriate credit is given, any changes made indicated, and the use is non-commercial. See: http://creativecommons.org/licenses/by-nc/4.0/.

\section{REFERENCES}

1. Corn AL, Koenig AJ. Foundations of low vision: clinical and functional perspectives 1996;474.

2. World Health Organization. International classification of functioning, disability, and health : ICF. Geneva: World Health Organization, 2001.

3. Berger S, Porell $\mathrm{F}$. The association between low vision and function. $J$ Aging Health 2008;20:504-25. 0898264308317534 [pii].

4. Leissner J, Coenen M, Froehlich S, et al. What explains health in persons with visual impairment? Health Qual Life Outcomes 2014;12:65-16.

5. Horowitz A. The prevalence and consequences of vision impairment in later life. Top Geriatr Rehabil 2004;20:185-95.

6. Rovner BW, Casten RJ, Hegel MT, et al. Preventing depression in age-related macular degeneration. Arch Gen Psychiatry 2007;64:886-92. 64/8/886 [pii].

7. Rovner BW, Zisselman PM, Shmuely-Dulitzki Y. Depression and disability in older people with impaired vision: a follow-up study. $J$ Am Geriatr Soc 1996;44:181-4.

8. Rovner BW, Casten RJ. Activity loss and depression in age-related macular degeneration. The American Journal of Geriatric Psychiatry 2002;10:305-10.

9. Renaud J, Levasseur M, Gresset J, et al. Health-Related and subjective quality of life of older adults with visual impairment. Disabil Rehabil 2010;32:899-907. 10.3109/09638280903349545 [pii].

10. Desrosiers J, Wanet-Defalque M-C, Témisjian $\mathrm{K}$, et al. Participation in daily activities and social roles of older adults with visual impairment. Disabil Rehabil 2009;31:1227-34.

11. Bullimore MA, Bailey IL, Wacker RT. Face recognition in age-related maculopathy. Investig Ophthalmol Vis Sci 1991;32:2020-9.

12. Johnson AP, Woods-Fry H, Wittich W. Effects of magnification on emotion perception in patients with age-related macular degeneration. Invest. Ophthalmol. Vis. Sci. 2017;58.

13. Tejeria Let al. Face recognition in age related macular degeneration: perceived disability, measured disability, and performance with a bioptic device. Br J Ophthalmol 2002;86:1019-26.
14. Holt-Lunstad J, Smith TB, Layton JB, et al. And mortality risk: a meta-analytic review. PLoS Med 2010;7:e1000316.

15. Binns AM, Bunce C, Dickinson C, et al. How effective is low vision service provision? A systematic review. Surv Ophthalmol 2012;57:34-65

16. Wittich W, Murphy C, Mulrooney D. An adapted adult day centre for older adults with sensory impairment. British Journal of Visual Impairment 2014;32:249-62.

17. Lamoureux EL, Pallant JF, Pesudovs K, et al. The effectiveness of Low-Vision rehabilitation on participation in daily living and quality of life. Invest. Ophthalmol. Vis. Sci. 2007;48:1476-81.

18. Lamoureux EL, Pallant JF, Pesudovs K, et al. Assessing participation in daily living and the effectiveness of Rehabiliation in age related macular degeneration patients using the impact of vision impairment scale. Ophthalmic Epidemiol 2008;15:105-13.

19. Southall K, Wittich W. Barriers to low vision rehabilitation: a qualitative approach. J Vis Impair Blind 2012;106:261-74.

20. Fraser SA, Kenyon V, Lagacé M, et al. Stereotypes associated with age-related conditions and assistive device use in Canadian media: table 1. Gerontologist 2016;56:1023-32.

21. Crocker J, Major B, Steele C, et al. In: Gilbert DT, Fiske ST, Lindzey $G$, eds. The handbook of social psychology. New York, NY: McGrawHill, 1998: 504-53.

22. Iyer A, Sen G, Östlin P. The intersections of gender and class in health status and health care. Glob Public Health 2008;3 Suppl 1:13-24.

23. Green S, Davis C, Karshmer E, et al. Living stigma: the impact of labeling, Stereotyping, separation, status loss, and discrimination in the lives of individuals with disabilities and their families. Sociol Inq 2005;75:197-215.

24. Treloar LL. People with Disabilities - the same, but different: implications for health care practice. $J$ Transcult Nurs 1999;10:358-64.

25. Vision S-SC, Adults O. J Gay Lesbian Soc Serv 2002;13:95-101.

26. Frable DES, Platt L, Hoey S. Concealable stigmas and positive selfperceptions: feeling better around similar others. J Pers Soc Psychol 1998;74:909-22.

27. Richardson SA, Goodman N, Hastorf AH, et al. Cultural uniformity in reaction to physical disabilities. Am Sociol Rev 1961;26:241-7.

28. Joachim G, Acorn S. Stigma of visible and invisible chronic conditions. J Adv Nurs 2000;32:243-8.

29. Joachim G, Acorn S. Living with chronic illness: the interface of stigma and normalization. Can J Nurs Res 2000;32:37-48.

30. Ryan EB, Giles H, Bartolucci G, et al. Psycholinguistic and social psychological components of communication by and with the elderly. Lang Commun 1986;6:1-24.

31. Harwood J, Giles H, Fox S, et al. Patronizing young and elderly adults: response strategies in a community setting. Journal of Applied Communication Research 1993;21:211-26.

32. Edwards NI, Jones DA. Ownership and use of assistive devices amongst older people in the community. Age Ageing 1998;27:463-8.

33. Levy BR, Zonderman AB, Slade MD, et al. Age stereotypes held earlier in life predict cardiovascular events in later life. Psychol Sci 2009;20:296-8.

34. Levy BR, Slade MD, Gill TM. Hearing decline predicted by elders' stereotypes. The Journals of Gerontology Series B: Psychological Sciences and Social Sciences 2006;61:P82-P87.

35. Ozanne JL, Saatcioglu B. Participatory action research. J Consum Res 2008;35:423-39.

36. Beverley CA, Bath PA, Barber R. Can two established information models explain the information behaviour of visually impaired people seeking health and social care information? Journal of Documentation 2007;63:9-32.

37. Renaud J, Bédard E. Depression in the elderly with visual impairment and its association with quality of life. Clin Interv Aging 2013;8:931-43

38. Bunting C. Public attitudes to deafness. London: Department of Health and Social Security, 1981.

39. Sharts-Hopko NC, Smeltzer S, Ott BB, et al. Healthcare experiences of women with visual impairment. Clinical Nurse Specialist 2010;24:149-53.

40. Orzolek-Kronner C, Desimone J. Seeing through the eyes of the blind: Psychodynamically informed work with perspns with low vision.. In: Berzof J, ed. Falling through the cracks: Psychodynamic practice with vulnerable and Oppressed populations. New York: NY: Columbia University Press, 2011.

41. Dovidio JF, Major B, Crocker J, et al. Stigma: introduction and overview. In: Heatherton TF, Kleck RE, Hebl MR, et al, eds. To social psychology of stigma. New York: Guilford press, 2000.: 1-32.

42. Wagner-Lampl A, Oliver GW. Folklore of blindness. J Vis Impair Blind 1994;88:267-76. 
43. Kent $D$. Shackled imagination: literary illusions about blindness. $J$ Vis Impair Blind 1989;83:145-50.

44. Goffman E. Stigma: Notes on the management of spoiled identity. New Jersey: Prentice Hall, 1963.

45. Crocker J, Quinn D, et al. Social stigma and the self: Meanings, situations, and self-esteem. In: Heatherton T, Kleck R, Hebl M, et al, eds. The social psychology of stigma. New York, New York, USA: Guilford Press, 2000: 153-83.

46. Ward AL. The response of individuals beginning to work with blind persons. New Outlook Blind 1973;67:1-5.

47. Heaton J. Secondary analysis of qualitative data: an overview. Hist Soc Res 2008;33:33-45.

48. Szabo V, Strang VR. Secondary analysis of qualitative data. ANS Adv Nurs Sci 1997;20:66-74.

49. Tong A, Sainsbury P, Craig J. Consolidated criteria for reporting qualitative research (COREQ): a 32-item checklist for interviews and focus groups. Int J Qual Health Care 2007;19:349-57.

50. Overbury $\mathrm{O}$, Wittich W. Barriers to low vision rehabilitation: the Montreal barriers study. Invest Ophthalmol Vis Sci 2011;52:8933-8.

51. Morse J, Field PA. Qualitative research methods for health professionals. In: Oaks T, Sage CA, eds. 2Nd, 1995.

52. Elo $S$, Kyngäs $H$. The qualitative content analysis process. $J$ Adv Nurs 2008;62:107-15.

53. Polit DF, Beck CT. Nursing research: Principles and methods. Philadelphia, PA: Lippincott Williams \& Wilkins, 2004.

54. Hsieh H-F, Shannon SE. Three approaches to qualitative content analysis. Qual Health Res 2005;15:1277-88.

55. Burnard P. A method of analysing interview transcripts in qualitative research. Nurse Educ Today 1991;11:461-6.

56. Scientific Software Development Inc. Atlas-ti 6.0 (computer program. Berlin, Germany: GmbH, 2009.

57. Wittich W, Jarry J, Groulx G, et al. Rehabilitation and research priorities in Deafblindness for the next decade. J Vis Impair Blind 2016;110:219-31.

58. Wittich W, Southall K. Coping with extended facedown positioning after macular hole surgery: a qualitative diary analysis. Nurs Res 2008; $57: 436-43$

59. Wittich W, Höbler F, Jarry J, et al. Recommendations for successful sensory screening in older adults with dementia in long-term care: a qualitative environmental scan of Canadian specialists. BMJ Open 2018;8:e019451.

60. Tolman J, Hill RD, Kleinschmidt JJ, et al. Psychosocial adaptation to visual impairment and its relationship to depressive affect in older adults with age-related macular degeneration. Gerontologist 2005:45:747-53.

61. Christy B, Nirmalan PK. Research reports: acceptance of the long cane by persons who are blind in South India. J Vis Impair Blind 2006:100:115-9.

62. Bennion AE, Shaw RL, Gibson JM. What do we know about the experience of age related macular degeneration? A systematic review and meta-synthesis of qualitative research. Soc Sci Med 2012;75:976-85.

63. Livneh H, Chan F, Kaya C. Stigma related to physical and sensory disabilities. In: Corrigan PW, ed. The stigma of disease and disability : Understanding causes and overcoming injustices. American Psychological Association, 2014: 93-120.
64. Corn AL, Koenig AJ. Foundations of Low Vision: Clinical and Functional Perspectives. 2nd edn. New York: NY, 2010.

65. Spafford MM, Laliberte Rudman D, Leipert BD, et al. When selfpresentation trumps access: why older adults with low vision go without low-vision services. J App/ Gerontol 2010;29:579-602.

66. Naraine MD, Lindsay PH. Social inclusion of employees who are blind or low vision. Disabil Soc 2011;26:389-403.

67. World Health Organization. World Report on Disability. Geneva, Switzerland: Author, 2011.

68. Kashdan TB, Rottenberg J. Psychological flexibility as a fundamental aspect of health. Clin Psychol Rev 2010;30:865-78.

69. Markowitz FE. Sociological Models of Mental Illness Stigma: Progress and Prospects. Washington, DC: American Psychological Association, 2005.

70. Steele CM, Spencer SJ, Aronson J. Contending with group image: the psychology of stereotype and social identity threat. Adv Exp Soc Psychol 2002;34:379-440.

71. Häfner M, Stapel DA. Familiarity can increase (and decrease) stereotyping: heuristic processing or enhanced knowledge usability? Soc Cogn 2009;27:615-22.

72. Smith ER, Miller DA, Maitner AT, et al. Familiarity can increase stereotyping. J Exp Soc Psychol 2006;42:471-8.

73. Aljied R, Aubin M-J, Buhrmann R, et al. Prevalence and determinants of visual impairment in Canada: cross-sectional data from the Canadian longitudinal study on aging. Canadian Journal of Ophthalmology 2018;53:291-7.

74. Maberley DAL, Hollands $\mathrm{H}$, Chuo J, et al. The prevalence of low vision and blindness in Canada. Eye 2006;20:341-6.

75. Colenbrander A. Aspects of vision loss - visual functions and functional vision. Vis Impair Res 2003;5:115-36.

76. Wainapel SF. Attitudes of visually impaired persons toward cane use. Vis Impair Blind 1989;83:446-8.

77. Bogart KR. The role of disability self-concept in adaptation to congenital or acquired disability. Rehabil Psychol 2014;59:107-15.

78. Conley-Jung C, Olkin R. Mothers with visual impairments who are raising young children. J Vis Impair Blind 2001;95:14-29.

79. Link BG, Phelan JC. Stigma and its public health implications. The Lancet 2006;367:528-9.

80. Story MF. Maximizing usability: the principles of universal design. Assistive Technology 1998;10:4-12.

81. Major B, O'Brien LT. The social psychology of stigma. Annu Rev Psychol 2005;56:393-421.

82. Abdou CM, Fingerhut AW, Jackson JS, et al. Healthcare stereotype threat in older adults in the health and retirement study. Am J Prev Med 2016;50:191-8.

83. Fraser S, Southall K, Wittich W. Exploring Professionals' Experiences in the Rehabilitation of Older Clients with Dual-Sensory Impairment. Can J Aging. In Press 2019.

84. Smallfield S, Lou JQ. The effectiveness of low vision rehabilitation on quality of life: an evidence-based practice approach to answer clinical questions. Occupational Therapy In Health Care 2006;20:17-30.

85. Smallfield S, Berger S, Hillman B, et al. Living with low vision: strategies supporting daily activity. Occupational Therapy In Health Care 2017;31:312-28. 